\title{
Do códige ao monitor: A trajetória do escrito
}

\author{
ROGER CHARTIER
}

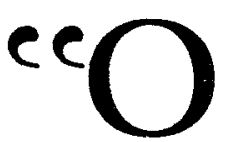

livro já não exerce o poder de que dispôs antigamente, já não é o mestre de nossos raciocínios e sentimentos em face dos novos meios de informaçáo e comunicaçáo, de que doravante dispomos" (1). Essa conclusão de Henri-Jean Martin constituirá o ponto de partida de minha reflexão, a qual pretende detectar e designar os efeitos de uma revolução, temida por alguns, aplaudida por outros, dada como inelutável ou simplesmente apontada como possível, ou seja, a alteração radical das modalidades de produçáo, transmissão e recepçáo do escrito. Dissociados dos suportes em que costumamos encontrá-los (o livro, o jornal, o periódico), os textos, de agora em diante, estariam fadados a uma existência eletrônica: compostos no computador ou numerizados, transmitidos por procedimentos teleinformáticos, eles alcançam um leitor, que os apreende num monitor.

Ao abordar esse futuro (que, taivez, já seja um presente), em que os textos são separados da forma com que o livro se impôs ao Ocidente, há dezessete ou dezoito séculos, meu ponto de vista será duplo. Será o de um historiador da cultura escrita, particularmente atento a reunir numa mesma história o estudo dos textos (canônicos ou comuns, literários ou desprovidos de qualidade), bem como dos suportes que os transmitiram e disseminaram, das leituras desses textos, de seus usos e interpretaçóes. Será, igualmente, o ponto de vista de um dos participantes (em nível modesto) do projeto da Bibliothèque de France. Com efeito, um dos eixos essenciais desse projeto é a constituição de um importante acervo de textos eletrônicos, os quais poderão ser transmitidos à distância e ser objeto de um novo tipo de leitura, possibilitada pelo posto de leitura assistido por computador.

Minha primeira pergunta será a seguinte: como, na longa história do livro e da relaçáo ao escrito, situar a revoluçáo anunciada, mas, na verdade, já iniciada, que se passa do livro (ou do objeto escrito), tal qual o conhecemos, com seus cadernos, folhetos, páginas, para o texto eletrônico e a leitura num monitor? Para responder a essa interrogação, cabe distinguir claramente três registros de mutaçóes, cujas relaçóes ficam ainda por estabelecer. A primeira revolução é técnica: ela modifica 
totalmente, nos meados do século XV, os modos de reproduçáo dos textos e de produçáo dos livros. Com os caracteres móveis e a prensa de imprimir, a cópia manuscrita deixa de ser o único recurso disponível para assegurar a multiplicaçáo e a circulaçáo dos textos. Daí, a ênfase dada a esse momento essencial da História ocidental, momento considerado como assinalando o aparecimento do livro ( $L$ 'apparition du lipre, esse é o título do livro pioneiro de Lucien Febvre e Henri-Jean Martin, publicado em 1958) (2), ou caracterizado como Printing Revolution (título da obra de Elizabeth Eisenstein, editado em 1983) (3).

Hoje, houve notável deslocamento da atençáo, salientando-se os limites dessa primeira revolução. Em primeiro lugar, é claro que, em suas estruturas fundamentais, o livro não é modificado pela invenção de Gutenberg. Por um lado, pelo menos até mais ou menos 1530, o livro impresso continua muito dependente do manuscrito: imita-lhe as paginaçóes, escritas, aparências; acima de tudo, exige-se que o acabamento do livro seja obra da máo do iluminador que pinta letras iniciais adornadas ou historiadas e miniaturas; a mão do corretor, ou emendator, que acrescenta sinais de pontuaçáo, rubricas e títulos; a máo do leitor, que inscreve na página notas e indicaçóes marginais (4). Por outro lado, e mais fundamentalmente, depois como antes de Gutenberg, o livro é um objeto composto de folhas dobradas, reunidas em cadernos, os quais, por sua vez, são encadernados. Nesse sentido, a revoluçáo da imprensa não é, de forma alguma, aparecimento do livro. Doze ou treze séculos antes da nova técnica, o livro ocidental já encontrara a forma que permaneceria idêntica na cultura do impresso.

Um olhar lançado para o Leste, para os lados da China, da Coréia, do Japão traz uma segunda razão para reavaliar a revoluçáo da imprensa. Ele, de fato, revela que a utilização da técnica própria do Ocidente não é condição necessária à existência de uma cultura, não somente de uma cultura escrita, mas também de uma cultura impressa, com base ampla (5). No Oriente, sem dúvida, os caracteres móveis săo conhecidos; lá, aliás, é que foram inventados e utilizados bem antes de Gutenberg: caracteres de argila cozida já são utilizados na China no século XI e, no século XIII, na Coréia, textos são impressos com caracteres metálicos. Mas, à diferença do Ocidente depois de Gutenberg, a utilizaçăo dos caracteres móveis permanece, no Oriente, limitada, descontínua, confiscada pelo imperador ou pelos mosteiros, o que, assim mesmo não significa a ausência de uma cultura do impresso de larga envergadura. $O$ que a tornou possível foi outra técnica, a xilografia, ou seja, a gravura em madeira de textos impressos em seguida por fricção. Atestada desde os meados do século VIII, na Coréia, e, no fim do século IX, na China, a xilografia propicia, na China das dinastias Ming e Qing, assim como 
no Japáo dos Tukogawa, uma circulaçâo muito ampla do escrito impresso, com empresas de ediçóes comerciais independentes dos poderes, uma rede densa de livrarias e gabinetes de leitura, gêneros populares amplamente divulgados.

Náo se deve, portanto, medir a cultura impressa das civilizaçóes orientais pela mesma medida da técnica ocidental, ou seja, como que ressaltando as lacunas da primeira. A xilografia tem suas vantagens próprias, está mais bem adaptada do que os caracteres móveis a línguas cujos traços marcantes sáo o grande número de caracteres, ou como no Japão, a pluralidade das escritas; ela mantém uma ligação forte entre a escrita manuscrita e a impressáo, uma vez que as pranchas gravadas o sáo a partir de modelos caligrafados; pela própria resistência das madeiras, conservadas de forma duradoura, ela permite a adequação da tiragem à demanda. Uma constatação como essa deve conduzir a uma apreciaçáo mais justa da invenção de Gutenberg. Fundamental, é verdade, essa não é a única técnica capaz de assegurar uma disseminação, em grande escala, do livro impresso.

A revoluçáo do nosso presente é, com toda certeza, mais que a de Gutenberg. Ela não modifica apenas a técnica de reprodução do texto, mas também as próprias estruturas $\mathrm{e}$ formas do suporte que o comunica a seus leitores. O livro impresso tem sido, até hoje, o herdeiro do manuscrito: quanto à organizaçáo em cadernos, à hierarquia dos formatos, do libro da banco ao libellus; quanto, também, aos subsídios à leitura: concordâncias, índices, sumários etc. (6). Com o monitor, que vem substituir o códice, a mudança é mais radical, posto que são os modos de organizaçáa, de estruturaçáo, de consulta do suporte do escrito que se acham modificados. Uma revolução desse porte necessita, portanto, outros termos de comparaçáo.

A história longa da leitura fornece-nos elementos essenciais. Sua cronologia organiza-se a partir da identificaçáo de duas mutaçóes fundamentais. A primeira dá ênfase a uma transformaçāo da modalidade física, corporal do ato de leitura e insiste na importância decisiva da passagem de uma leitura necessariamente oralizada, indispensável ao leitor para a compreensão do sentido, a uma leitura possivelmente silenciosa e visual (7). Tal revolução diz respeito à longa Idade Média, já que a leitura silenciosa, inicialmente restrita aos scriptoria monásticos entre os séculos VII e XI, chega às escolas $\mathrm{e}$ às universidades no século XII e, depois, às aristocracias legais, dois séculos mais tarde. Sua condição é a introdução, pelos escribas irlandeses e anglo-saxônicos da Alta Idade Média, da separaçáo entre as palavras; seus efeitos são verdadeiramente consideráveis, abrindo-se a possibilidade de ler com mais rapidez e, portanto, de ler mais textos e textos mais complexos. 
Uma perspectiva como essa sugere duas observaçóes. Primeiro, o fato de o Ocidente medieval ter sido obrigado a conquistar a competência da leitura em sillencio e com os olhos, não deve nos levar à conclusáo de que esta inexistiu na Antiguidade grega e romana. Nas civilizaçóes antigas, em se tratando de populaçóes para as quais a língua é a mesma que a língua vernacular, a ausência de separaçáo entre as palavras não próbe, de modo algum, a leitura silenciosa (8). A prática, comum na Antiguidade, da leitura em voz alta, para os outros e para si mesmo, não deve, portanto, ser atribuída à falta de domínio da leitura com os olhos apenas (essa é provavelmente praticada no mundo grego desde o século VI a.C.) (9), mas a uma convenção cultural que associa fortemente o texto e a voz, a leitura, a declamação e a escuta (10). Tal traço subsiste, aliás, na época moderna, entre os séculos XVI e XVIII, quando ler em silencio tornou-se uma prática comum dos leitores letrados. A leitura em voz alta permanece, então, o cimento fundamental das diversas formas de sociabilidade: familiares, eruditas, públicas, mundanas, e o leitor visado por grande número de gêneros literários é um leitor que lê para outros ou um leitor que ouve ler. Na Castela do Século de Ouro, leer e oir, ver e escuchar são quase sinônimos e a leitura em voz alta é a leitura implícita de gêneros bastante diversos: todos os gêneros poéticos, a comédia humanista (lembremo-nos da Celestina), o romance em todas suas formas, até ao Quixote, a própria História (11).

Segunda observação em forma de pergunta: Não é que se deveria dar mais importância às funçóes do escrito do que a seu modo de leitura? Sendo afirmativa a resposta, uma censura essencial tem de ser colocada no século XII, quando se atribui ao escrito não apenas uma função de conservaçáo e memorização, já que é composto e copiado com vistas a uma leitura, entendida como um trabalho intelectual. A um modelo monástico da escrita sucede, nas escolas e universidades, um modelo escolástico. No mosteiro, o livro não é copiado para ser lido, ele tesouriza o saber como um bem patrimonial da comunidade e veicula usos antes de tudo religiosos: a ruminatio do texto, verdadeiramente incorporado pelo fiel, a meditação, a oraçáo. Com o aparecimento das escolas urbanas, tudo muda: o lugar de produçáo do livro, que passa do scriptorium à loja do stationnarius; as formas do livro, com a multiplicação das abreviaturas, indicaçóes, glosas e comentários, enfim o próprio método de leitura, que já não é participaçáo no mistério da Palavra, mas deciframento regulado e hierarquizado da letra (littera), do sentido (sensus) e da doutrina (sententia) (12). As conquistas da leitura silenciosa não podem, portanto, ser separadas da mutaçáo maior que transforma a própria função da escrita.

Outra repolufgño da leitura é a que diz respeito ao estilo de leitura; 
na segunda metade do século XVIII, à leitura intensiva haveria de suceder outra, qualificada de extensipa (13). O leitor intensipo é confrontado com um corpus limitado e fechado de textos lidos e relidos, memorizados e recitados, ouvidos e sabidos de cor, transmitidos de geração a geração. Os textos religiosos, e em primeiro lugar a Bíblia nos países protestantes, são os alimentos privilegiados desta leitura, fortemente marcada pela sacralidade e autoridade. O leitor extensipo, o da Lesenvut, da ânsia da leitura que toma conta da Alemanha no tempo de Goethe, é um leitor totalmente outro: ele consome muitos e variados impressos; lê-los com rapidez e avidez, exerce em relação a eles uma atividade crítica que, agora, submete todas as esferas, sem exceção, à dúvida metódica.

É verdade que semelhante diagnóstico tem sido questionado. De fato, no tempo da leitura intensiva, há muitos leitores extensipos: lembremo-nos dos letrados humanistas, que acumulam as leituras para compor seus cadernos de lugares-comuns (14). E o inverso também é verdade e mais ainda: no momento mesmo da revolufão da leitura, com Rousseau, Goethe e Richardson, é que realmente, desdobra-se a mais intensiva das leituras, aquela por que o romance apodera-se de seu leitor, o prende e governa, como o fazia antes o texto religioso (15). Por outro lado, para o grupo mais extenso dos leitores, para os mais humildes - os dos chapbooks, da Bibliothèque bleue ou da literatura de cordel, a leitura conserva, de forma duradoura, os traços de uma prática rara, difícil, que supõe memorização e recitação de textos, os quais, devido a seu número restrito, se lhes tornam familiares, sendo, na verdade, antes reconhecidos que descobertos.

Tais precauçóes - necessárias - , que levam a abandonar a visão de uma oposição rígida demais entre os dois estilos de leitura, nem por isso invalidam as conclusóes que situam na segunda metade do século XVIII uma repolufá̃o da leitura, cujos suportes são detectados, de forma clara, na Inglaterra, na Alemanha e na França: assim o crescimento da produçáo do livro, a multiplicaçáo e a transformação dos jornais, o sucesso dos pequenos formatos, a diminuiçáo do preço dos livros graças às contrafações, a multiplicação das sociedades de leitura (bookclubs, Lesegesellschaften, cabinets de lecture). Descrita como uma ameaça à ordem política, um narcótico (é a palavra usada por Fichte) ou como um desregramento da imaginação e dos sentidos essa ansia de leitura chama a atenção dos observadores contemporâneos. Preenche, sem dúvida alguma, um papel essencial nos desligamentos críticos que, por toda a parte na Europa, especialmente na França, afastam os súditos do príncipe e os cristãos de suas igrejas. 
A revolução do texto eletrônico será, ela também, uma revoluçáo da leitura. Ler num monitor não é o mesmo que ler num códice. Se é verdade que abre possibilidades novas e imensas, a representaçáo eletrônica dos textos modifica totalmente a condição destes: à materialidade do livro, ela substitui a imaterialidade de textos sem lugar próprio; às relaçōes de contigüidade estabelecidas no objeto impresso, ela opóe a livre composiçáo de fragmentos indefinidamente manipuláveis; à apreensão imediata da totalidade da obra, viabilizada pelo objeto que a contém, ela faz suceder a navegafáo de muito longo curso, por arquipélagos textuais sem beira nem limites (16). Essas mutações comandam, inevitável e imperativamente, novas maneiras de ler, novas relaçóes com o escrito, novas técnicas intelectuais. Se as precedentes revoluçōes da leitura ocorreram em épocas nas quais as estruturas fundamentais do livro não mudavam, não é o que se dá no nosso mundo contemporâneo. A revolução iniciada $e ́$, antes de tudo, uma revolução dos suportes e das formas que transmitem o escrito. Nesse ponto, ela tem apenas um precedente no mundo ocidental: a substituiçáo do volume pelo códice, do livro em forma de rolo, nos primeiros séculos da era cristá, pelo livro composto de cadernos juntados.

A respeito desta revoluçăo primeira, a qual inventa o livro que ainda é o nosso, três questóes devem ser levantadas (17). Primeiro, a de sua data. Os dados arqueológicos disponíveis, fornecidos por escavaçóes efetuadas no Egito, permitem chegar a várias conclusōes. Por um lado, é nas comunidades cristãs que, de forma precoce e maciça, o rolo vai sendo substituído pelo códice: desde o século II, todos os manuscritos da Bíblia encontrados são códices escritos em papiros; $90 \%$ dos textos bíblicos e $70 \%$ dos textos litúrgicos e hagiográficos dos séculos II-IV que chegaram até nós apresentam-se na forma do códice. Por outro lado, é com sensível defasagem que os textos gregos, literários ou científicos, adotam a nova forma do livro. É preciso esperar o período dos séculos III e IV para que o número de códices se iguale com o dos rolos. Mesmo se a dataçáo dos textos bíblicos sobre papiros tem sido questionada e, por vezes, retardada, até o século III, permanece forte o laço que vincula ao cristianismo a preferência dada ao códice.

Uma segunda questáo é a das razóes da adoçáo desta forma nova do livro. Os motivos classicamente apontados, embora devam ser de algum modo reavaliados, conservam sua pertinência. A utilização dos dois lados do suporte reduz, sem dúvida, o custo de fabricaçáo do livro, mas ela não foi acompanhada por outras possíveis economias: diminuiçăo do módulo da escrita, estreitamento das margens etc. Por outro lado, o códice permite, incontestavelmente, reunir uma grande quantidade de texto num volume menor, mas tal vantagem pouco foi apro- 
veitada de imediato: nos primeiros séculos de sua existência, os códices permanecem de tamanho modesto, comportam menos de centro e cinqüenta folhetos, ou seja, trezentas páginas. Só a partir do século IV, até mesmo do século $\mathrm{V}$, é que os códices tornam-se mais grossos e absorvem o conteúdo de vários rolos. Finalmente, é inegável que o códice ajuda na localização do texto, agiliza seu manejo: possibilita a paginação, a criaçáo de índices e concordâncias, a comparação de uma passagem com outra, ou, ainda, permite ao leitor que o folheia percorrer o livro por inteiro. Daí, a adaptação da forma nova do livro às necessidades textuais próprias do cristianismo, ou sèja, a confrontaçáo dos Evangelhos e a mobilizaçăo, para os fins da pregação, do culto ou da oração, de citaçóes da Palavra sagrada. Mas, fora dos ambientes cristáos, o domínio e a utilizaçăo das possibilidades oferecidas pelo códice não se impóem senão lentamente. Parece que aqueles que preferencialmente adotam o códice são aqueles que não pertencem à elite culta - a qual permanece fiel, de modo duradouro, aos modelos gregos, portanto ao polume - e tal adoçáo diz respeito primeiro a textos situados fora do cânone literário: textos escolares, obras técnicas, romances etc.

Entre as consequiências da passagem do rolo ao códice, duas merecem atenção especial. Por um lado, se o códice impóe sua materialidade, nem por isso apaga as designaçōes ou representaçóes antigas do livro. Em a Cidade de Deus de Santo Agostinho, por exemplo, se o termo códice denomina o livro enquanto objeto físico, a palavra liber é usada para assinalar as divisóes da obra, conservando-se assim a memória da antiga forma, já que o livro, que, neste caso, é a unidade do discurso (a Cidade de Deus comporta vinte e duas dessas unidades), correspondente à quantidade de texto que podia conter um rolo (18). Da mesma forma, as representaçóes do livro nas moedas e nos monumentos, na pintura e na escultura, permanecem duravelmente ligadas ao volume, símbolo de saber e autoridade, apesar de o códice já ter imposto sua materialidade e obrigado a novas práticas de leitura. Por outro lado, para ser lido - e, portanto, desenrolado - um rolo deve ser segurado com as duas máos: daí, como o mostram afrescos e baixos-relevos, a impossibilidade para o leitor de escrever e ler ao mesmo tempo, e conseqüentemente, a importância do ditado em voz alta. É graças ao códice que o leitor conquista a liberdade: colocado numa mesa ou púlpito, o livro reunido em cadernos já náo exige uma total mobilizaçáo do corpo, proporciona maior independência ao leitor que pode ler e escrever ao mesmo tempo, passar, a seu bel prazer, de uma página a outra, de um livro a outro. É com o códice, igualmente, que se inventa a tipologia formal que associa formatos e gêneros, tipos de livros e categorias de discursos, e, portanto, instala-se o sistema de identificação e localizaçăo 
dos textos, do qual a imprensa será herdeira e que conservamos até hoje (19).

Por que esses olhares para trás, por que, especialmente, a atenção dada ao nascimento do códice? Provavelmente porque a compreensão e o domínio da revoluçáo eletrônica de amanhấ (ou de hoje), depende amplamente de sua concreta inscrição em uma história de longa duraçáo, a qual permite tomar plenamente consciência de todas as possibilidades inéditas, abertas pela numerização dos textos, sua transmissão pela teleinformática e sua recepção em computador. No mundo dos textos eletrônicos ou, mais exatamente, da representaçáo eletrônica dos textos, duas sujeições, tidas até agora como imperativas, podem ser eliminadas. Primeira sujeiçáo: a que limita rigorosamente as possíveis intervençóes do leitor no livro impresso. Desde o século XVI, isto é, desde a época em que o impressor encarregou-se dos sinais, marcas e títulos, títulos de capítulos ou títulos comuns - enquanto, no tempo dos incunábulos, esses eram acrescentados à mão na página impressa pelo corretor ou pelo possuidor do livro -, o leitor só pode insinuar sua escrita nos espaços virgens do livro. $O$ objeto impresso impóe-lhe sua forma, sua estrutura, suas disposições e não supóe, de modo algum, sua participaçáo. Se, assim mesmo, o leitor pretende inscrever sua presença no objeto, só pode fazê-lo ocupando, sub-reptícia e clandestinamente, os lugares do livro preteridos pela escrita: interiores da encadernaçáo, folhetos deixados em branco, margens do texto etc. (20).

Com o texto eletrônico, a coisa muda. Náo somente o leitor pode submeter o texto a múltiplas operaçóes (pode indexá-lo, colocar observações, copiá-lo, desmembrá-lo, recompô-lo, deslocá-lo etc.), mas pode ainda tornar-se seu co-autor. A distinçăo, fortemente visível no livro impresso, entre a escrita e a leitura, entre o autor do texto e o leitor do livro, desaparece diante de uma realidade diferente: a em que o leitor transforma-se em um dos atores de uma escrita a várias vozes ou, pelo menos, acha-se em condiçóes de constituir um texto novo, partindo de fragmentos livremente recortados e ajuntados. Da mesma forma que o leitor do manuscrito, que podia reunir em um só livro obras de natureza bastante diversa, reunidas no mesmo suporte, num mesmo libro-zibaldone, apenas pela própria vontade, o leitor da idade eletrônica pode construir, a seu bel prazer, conjuntos textuais originais, cuja existência e organização só dependem dele. Mas, além disso, ele pode, a qualquer momento, intervir nos textos, modificando-os, reescrevendo-os, fazendo-os seus. Compreende-se, entáo, que tal possibilidade questiona e ameaça as categorias usadas por nós para descrever as obras, referidas desde o século XVIII a um ato criador individual, singular e original, e que fundam o direito em matéria de propriedade literária. A noçáo de 
copyright, entendida como o direito de propriedade do autor sobre uma obra original, produzida por seu gênio criador (a primeira ocorrência do termo é de 1728) (21), ajusta-se mal com os modos de constituiçáo dos bancos de dados eletrônicos. Assim é que a Corte suprema dos Estados Unidos negou-lhe qualquer pertinência para a publicaçăo das listas telefônicas (22).

Por outro lado, o texto eletrônico, pela primeira vez, permite superar uma contradição que obsedou os homens do Ocidente: a que opōe de um lado o sonho de uma biblioteca universal que congregasse todos os livros já publicados, todos os textos já escritos, até mesmo, segundo Borges, todos os livros possíveis de serem escritos, esgotando todas as combinaçóes das letras do alfabeto e, de outro, a realidade, forçosamente decepcionante, de acervos, que, por maiores que sejam, só podem fornecer uma imagem parcial, mutilada do saber universal (23). O Ocidente deu uma figura exemplar e mítica a essa nostalgia da exaustividade perdida: a da biblioteca de Alexandria (24). A comunicaçáo à distância dos textos, a qual anula a distinção, até agora irremediável, entre o lugar do texto e o lugar do leitor, torna possível, acessível, esse sonho antigo. Sem materialidade, sem localização, o texto, em sua representaçáo eletrônica, pode alcançar qualquer leitor equipado do material necessário para recebê-lo. Supondo-se numerizados ou, em outras palavras, convertidos em textos eletrônicos, todos os textos existentes, sejam eles manuscritos ou impressos, é a universal disponibilidade do patrimônio escrito que se torna possível. Todo leitor, no lugar em que se encontra, com condiçáo que seja diante de um posto de leitura conectado com a rede que efetua a distribuiçáo dos documentos informatizados, poderá consultar, ler, estudar qualquer texto, independentemente de sua localização original (25). "Quando se proclamou que a Biblioteca abrangia todos os livros, a primeira reaçáo foi uma felicidade extravagante" (26): essa felicidade extravagante a que se refere Borges, nos é prometida pelas bibliotecas sem muros e até sem lugar, que serão provavelmente as de nosso futuro.

Felicidade extravagante, mas não sem risco, talvez. Pois, cada forma, cada suporte, cada estrutura da transmissão e da recepçáo do escrito afeta-lhe profundamente os possíveis usos, as possíveis interpretaçōes. Nesses últimos anos, a história do livro esforçou-se por descobrir, em diversos níveis, tais efeitos de sentido das formas (27). São muitos os exemplos que mostram como transformaçóes propriamente tipográficas (no sentido amplo da palavra) modificam profundamente os usos, as circulaçóes, as compreensóes de um mesmo texto. Assim, as variaçóes que aparecem nas divisóes do texto bíblico, especialmente a partir das ediçóes de Robert Estienne com seus versículos numerados. 
Assim, a imposição de dispositivos próprios do livro impresso (título e página de rosto, divisão em capítulos, madeiras gravadas) a obras cuja forma primeira, ligada a uma circulaçăo unicamente manuscrita, era-lhes totalmente estranha: é, por exemplo, a sorte do Lazarillo de Tormes, carta apócrifa, sem título, sem capítulo, sem ilustração -, destinado a um público culto, transformado por seus primeiros editores num livro próximo, por sua apresentação, das vidas de santos e dos escritores de ocasião, portanto, dos gêneros de maior circulaçăo na Espanha do Século de Ouro (28). Assim, na Inglaterra, para as obras teatrais, a passagem das ediçóes elisabetanas, rudimentares e compactas, às ediçóes que, no início do século XVIII, adotando as convençôes clássicas francesas, tornam visível a divisão em atos e cenas, restituindo, pelas indicaçóes dos jogos de cena, algo da ação teatral, no texto impresso (29). Assim, as formas novas dadas a todo um conjunto de textos já publicados, no mais das vezes de origem erudita, a fim de que pudessem atingir os leitores mais populares e constituir o repertório das livrarias de literatura de cordel em Castela, Inglaterra ou França. A conclusão é sempre idêntica: a significaçăo ou, antes, as significaçóes, histórica e socialmente diferenciadas de um texto, seja qual for, não podem ser separadas das modalidades materiais por meio de que o texto é oferecido aos leitores.

Daí, para o nosso presente, uma forte lição: a possível transferência do patrimônio escrito de um suporte para outro, do códice para - monitor, abre possibilidades imensas, mas constituirá também uma violência praticada sobre os textos, separados das formas que contribuíram a construir suas significaçōes históricas. Supondo-se que, num futuro mais ou menos próximo, as obras de nossa tradiçáo não fossem mais comunicadas e decifradas, a não ser numa representaçáo eletrônica, grande seria o risco de ver perdida a inteligibilidade de uma cultura textual em que um vínculo antigo, essencial, foi estabelecido entre o próprio conceito de texto e uma forma particular do livro: o códice. Nada melhor para manifestar a força de tal vínculo que as metáforas, que, na tradiçáo ocidental, fazem do livro uma figura possível do destino, do cosmos ou do corpo humano (30). O livro que elas manejam, de Dante a Shakespeare, de Raimundo Lúlio a Galileu, não é um livro qualquer: é composto por cadernos, formado de folhetos e páginas, protegido por uma encadernaçáo. A metáfora do livro do mundo, do livro da natureza, tão poderosa na idade moderna, acha-se como que vinculada às representaçóes imediatas e enraizadas que associam naturalmente o escrito ao códice. $O$ universo dos textos eletrônicos significará, forçosamente, um distanciamento com relação às representaçōes mentais e operações intelectuais especificamente ligadas às formas que 
tem apresentado o livro no Ocidente durante esses últimos dezessete ou dezoito séculos. Não há ordem dos discursos que seja separável da ordem dos livros que lhe é contemporânea.

Ao que me parece, é necessário ater-nos a duas exigências. Por um lado, é preciso acompanharmos, com uma reflexão histórica, jurídica e filosófica, a mutaçáo considerável que vem revolucionando os modos de comunicação e recepção do escrito. Uma revoluçăo técnica năo se decreta; tampouco se suprime. O códice levou a melhor e suplantou o rolo - embora este, em outra forma e para outros usos (particularmente arquivísticos) tivesse atravessado toda a Idade Média. E a imprensa substitui o manuscrito como forma maciça de reproduçáo e difusáo dos textos - embora o escrito copiado à mão tivesse conservado todo o seu papel, na idade do impresso, no tocante à circulaçáo de numerosos tipos de textos, oriundos da escrita do foro privado, das práticas literárias aristocráticas comandadas pela figura do gentleman-writer, ou das necessidades de comunidades particulares: aquelas designadas como heréticas, ligadas pelo segredo, das corporações de companheiros à francomaçonaria, ou, simplesmente, cimentadas pela circulação de textos manuscritos (31). Pode-se pensar, então, que no século XXV, naquele ano de 2440 em que Louis-Sébastien Mercier imaginou, em sua utopia publicada em 1771, a Biblioteca do Rei (ou da França) não seria um pequeno gabinete, em que estariam contidos apenas pequenos livros, os quais concentrariam o único saber útil (32), mas um ponto, numa rede estendida ao mundo inteiro, responsável pela universal distribuiçáo de um patrimônio textual, acessível por toda a parte graças à sua forma eletrônica. Chegou, portanto, a hora de melhor observar e compreender os efeitos de uma mutação desse porte e, tendo em vista que os textos não são necessariamente livros, nem mesmo periódicos ou jornais, derivados, eles também, do códice, de redefinirmos as noçốes jurídicas (propriedade literária, direitos autorais, copyright), regulamentares (depósito legal, biblioteconômicas (catalogaçăo, classificação, descrição bibliográfica etc.) que foram pensadas e construídas com relação a outra modalidade da produção, da conservação e comunicação do escrito.

Mas existe, para nós, uma segunda exigência, indissociável da precedente. A biblioteca do futuro deve ser, também, o lugar onde poderão ser mantidos o conhecimento e a compreensão da cultura escrita nas formas que foram e ainda sáo, majoritariamente, aquelas hoje conhecidas. A representação eletrônica de todos os textos, cuja existência não começa com a informática não deve, de modo algum, significar relegação, esquecimento, ou, pior ainda, destruição dos objetos que têm sido seus suportes. Mais do que nunca, talvez, uma das tarefas essenciais das grandes bibliotecas seja coletar proteger, recensear (por exemplo na 
forma de catálogos coletivos nacionais, primeiro passo em direção a bibliografias nacionais retrospectivas) e, também, tornar acessível a ordem dos livros que continua sendo a nossa e foi a dos homens e das mulheres que lêem desde os primeiros séculos da era cristá. Apenas se for preservada a inteligência da cultura do códice é que poderá existir, sem ressalva, a felicidade extrapagante prometida pelo monitor.

\section{Notas}

1 H.J. Martin, Le message écrit: la réception. Conferéncia dada na Académie des Sciences Morales et Politiques. Paris 15 de março de 1993.

2 L. Febvre \& H.-J. Martin, L'apparition du livre. Paris, Albin Michel, 1958.

3 E. Eisenstein, The printing revolution in early modem Europe, Cambridge, Cambridge University Press, 1983; versäo abreviada de The printing press as an agent of cbangl; comunications and cultural transformations in early modern Europe, Cambridge, Cambridge University Press, 1979.

$4 P$. Saenger, $M$. Heilein, Incunable description and its implication for the analysis of fifteenth-century reading habits. In: Printing the written world, the social bistory of books, circa 1450-1520 S. Mindman (ed.), Ithaca e Londres, Comell University Press, 1991, p. 225-258; M. M. Smith, Patterns of incomplete rubrication in incunables and what they suggest about working methods. In Mediepal book production, asseswing the ovidemet, L. L. Brownrigg (ed.), Los Altos Hills, Anderson-Lovelace, The Red Gull Press, 1990, p. 133-145.

5 Le livre at $l^{\prime}$ imprimeric on Extrtme-Orient et an Asie du Sud-Est, J-P. Drège, M. IshigamiIagolnitzer, M. Cohen (eds.), Bordeaux, Société des Bibliophiles de Guyenne, 1986; E. S. Rawski, Economic and social foundation of late Imperial China. In: Popular culture in late Imperial Cbina, D. Johnson A. Nathan, E.S. Rawski (ed.), Berkeley, University of California Press, 1985, p.3-33; Impressions de Chine, M. Cohen, N. Monnet (ed.), Paris, Bibliothèque Nationale, 1992.

6 A. Petrucci, Alle origine del libro moderno. Libri da banco, libri da biscaia, libreti da mano. In: Libri, scrittura e pubblico nel Rinascimento. Guida storica e critica, A. Petrucci (ed.), Roma-Bari, Laterza, 1979, p. 137-156.

7 P. Saenger, Silent reading: its impact on late Medieval script and society. Viator, Mer diepal and Renaisennce Studies, 13, 1982, p. 367-414; Physiologie de la lecture et skparation des mots, Amrales E. S. C., 1989, p. 939-952; The separation of words and order of words: the genesis of Medieval reading. Scritturn e Cipilith, XIV, 1990, p. 49-74.

8 B. Knox, Silent reading in antiquity, Greck, Roman and Byzantine Studies, IX, 1968, p. 421-435.

9 J. Svenbro, Pbrasikleir, antbropologie de la lecture en Grice ancienne, Paris, Editions de la Decouverte, 1988.

10 W. W. Harris, Ancient literacy, Cambridge, Mass. e Londres, Harvard University Press, 1989. 
11 M. Frenk, Lectores y ofdores. La difusión oral de la literatura en el Siglo de Oro, Actas del Septimo Congresso de la Asociación Internacional de Hispanistas, G. Bellini (ed.), Roma, Bulzoni, 1982, v. I, p. 101-123.

12 F. Alessio, Conservazione e modelli di sapere nell Medioevo. In: La memoria del sapere. Forme di conservazsione e strutture organizzative dall 'Antichiti a ogegi. P. Rossi (ed.), Roma-Bari, Laterza, 1988, p. 99-133.

13 R. Engelsing, Die perioden der Lesergeschichte in der Neuzeit. Das statistische Aumass und die soziokulturelle Bedeutung der Leknure, Archip fur Geschichte des Buchnoesens, 10, 1970, p. 945-1002. Cf. também as revisóes críticas de E. Schon, Dor Verlust der Sinnlicblecit oder Die Verwandlungen des Lesers. Mentalitatswandel um 1800, Stuttgart, Klett-Cotta, 1987; M. Nagl, Wandlungen das Lesens in der Aufklarung, Pladoyer fur einige Differenzierungen. In: Bibliotheken und Aufklarwng, W. Arnold, P. Vodosek (ed.), Wolfenbutteler schriften zur Gesschichte des Buchwesens, Band 14, Wiesbaden, In Kommission bei Otto Harrassowitz, 1988, p. 21-40; R. Wittman, Geschichte des deutschen Bucchandels, Munich, C. H. Beck, 1991.

14 A. Blair, Humanist methods in natural philosophy: the commonplace book. Jostrnal of bistory of ideas, v. 53, n. 4, Oct.-Dec. 1992, p. 541-551.

15 R. Darnton, Readers respond to Rousseau: the fabrication of romantic sensivity. In The great cat massacre and other episodes in French cultural history. New York, Basic Books, 1984, p. 215-256.

16 G. Nunberg, The places of books in the age of eletronic reproduction. Representations, 42; Future libraries, H. Bloch, C. Hesse (ed.), Spring 1993.

17 Cf. as observaçóes formuladas recentemente in Les debuts du codex, A. Blanchard (ed.), Turnhout, Brepols, 1989; dois artigos de G. Cavallo: Testo, libro, lettura. In: Lo spazio letterario di Roma antica, G. Cavallo, P. Fedeli, A. Giardina (eds.), Roma, Salerno Edtrice, v. II. La circolazione del testo, 1989, p. 307-341; Libro e cultura scritta. In: Storia di Roma, Torino, Einaudi, v. IV, Caratteri e morfologie, 1989, p. 693-734.

18 L. Holtz, Les mots latins désignant le livre au temps d'Augustin. In: Les débuts du codex, op. cit, p. 105-113.

19 A. Petrucci, Il libro manoscritto, Letteratura italiana, Torino, Einaudi, 2; Produzione e consumo, 1983, p. 499-524.

20 Marks in Books, Cambridge, Mass, The Houghton Library, 1985. Dois exemplos de análises das mençōes manuscritas no livro impresso in L. Jardine, A. Grafton, Studied for action: how Gabriel Harvey read his livy, Past and present, 129, Nov. 1990, p. 30-78; Cathy Davidson, Revolution and the word. The rise of the novel in Amtrica, New York e Oxford, Oxford University Press, 1986, p. 75-79. Um exemplo para o leitor manuscrito in R. Meyenberg, G. Ouy, Alain Chartier, lecteur d'Ovide, Scrittura e Civiltut, XIV, 1990, p. 75-103.

21 D. W. Nichol, On the use of copy and copyright: a scriblerian goinage?, The library. The transactions of the bibliographical society, Jun. 1990, p. 110-120.

22 P. Jaszi, On the author effect: contemporary copyright and collective creativity, Cardozo Arts and Entertinment Law Joumal, v. 10, n. 2, 1992; Intellectual property and the construction of authoship, p. 293-320; A. Prassoloff, Le droit d'auteur à l'âge de 
l'ecrit concurrence, Taxtuel, n. 25; Ecrite, voir, conter, p. 119-129: J. Ginsberg, Copyright without walls? Speculations on literary property in the lybrary of the future, $R$ presentations, 42; Funure libraries, Spring 1993.

23 R. Chartier, Bibliothèques sans murs. In: $L$ 'order des livres. Lecteuts, mutours, bibliothiqques en Europe cutre XIV e LXVIII c siecle, Aix en Provence, Alínea, 1992, p. 69-94; J. M. Goulemot, En guise de conclusion: les bibliothèques imaginaires (fictions romanesques et utopies), Histoire des bibliothiques fransaises, Paris, Promodis - Editions du Cercle de la Librairie, t. II, Les bibliothèques sous l'Ancien Régime, C. Jolly (ed.), 1989, p. 500-511.

24 L. Canfora, La biblioteca scomparsa, Palermo, Sellerio editore, 1986; Alecandric, III C siecle ap. J. C. Tous les sapoirs dus monde on le rete d iunipersalite des Ptolemtes, C. Jacob, F. de Polignac (ed.), Paris, Editions Autrement, 1992.

25 J. D. Bolter, Writing space: the computer, bypertext, and the bistory of writing, Hilsdale, 1991.

26 J. L. Borges, La biblioteca de Babel, 1941.

27 D. F. McKenzie, Bibliography and the sociology of texts, The Panizzi Lectures 1985, Londres, The British Library, 1986.

28 F. Rico, La princeps del Lazarillo. Tírulo, capitulación y epígrafes de un texto apócrifo. In: Problemas del Lazarillo, Madrid, Cátedra, 1988, p. 113-151.

29 D. F. Mckenzie, Typography and meaning: the case of William Congreve. In: Buch urd Buchbandel in Europa um achtzelsnten Jabrisundert, G. Barber, B. Fabian (ed.), Hamburgo, Dr Ernst Hauswedell und Co, 1981, p. 81-126.

30 E. R. Curtius, Europaische Literatur und Latoinisches Mittelalter, Bern, A. Francke AG Verlag, 1948, cap. 16; H. Blumenberg, Die Lesbarkeit des Welt, Frankfürt am Main, Suhrkamp, 1981.

31 Harold Love, Scribal publication in seventeenth-century England, Transactons of the Cambridge Bibliographical Society, v. IX, Part 2, 1987, p. 130-154; Francois Moureau, La plume et le plomb: la communication manuscrite au XVIII e siècle. In: Comrespondances litturaires inedites - etudes et extraits - suipies de Voltairiana, J. Schlobach (ed.), Paris-Genève, Champion-Slatkine, 1987, p. 21-30.

32 L.S. Mercier, $L$ 'an 2440. Repe s'il en fiut jamais, R. Trousson (ed.), Bordeaux, Editions Ducros, 1971, La bibliothèque du roi, p. 247-271.

\section{Resumo}

Estariam os textos, de agora em diante, fadados a uma existência eletrônica? Os livros, na forma que conhecemos, desde o século XVI, estariam condenados a desaparecer progressiva e definitivamente? Antes de responder a essas perguntas, Roger Chartier percorre a longa história do livro até aos nossos dias: do volumen ao códice, da xilografia oriental à invençäo de Gutenberg, da biblioteca de Alexandria até às nossas grandes bibliotecas modernas, do códice a monitor. A nossa época encontra-se diante de um desafio: o de utilizar de modo adequado o suporte eletrónico do escrito, pois os significados de um texto de- 
pendem muito do suporte material deste. A felicidude cotrapagante vislumbrada diante da produçăo, consulta, comunicaçáo imediata e universal de textos na telinha do computador deverá harmonizar-se com a consciéncia do papel reservado ao novo suporte: proteçăo, conservação e divulgação do património escrito da humanidade na sua materialidade tanto quanto na sua simbólica.

\begin{abstract}
Would texts, from now on, be fated to a mere electronic existence? Would books, in their format known since the sixteenth century, be condemned to disappear progressively and definitely? Before answering these questions we must follow the long history of books: from polumen to codex, from oriental xylography to Gutenberg's invention, from the Alexandrian bibliotheca to our great modern libraries, from codices to monitors. Our time faces a challenge: how to use appropriately the electronic support of writing, since the meanings of a text depend very much on its material support. The cxtrapagant bappiness gleamed before the production, the consultation, the immediate and universal communication of texts in the computer's screen should be in harmony with the conscience of the role reserved for the new support: protection, conservation and divulgation of the writing heritage of manking, both in its material and symbolic character.
\end{abstract}

Roger Chartier é professor da Escola de Altos Estudos em Ciências Sociais de Paris.

Traduçāo de Jean Briant. O original em francês - Du codex a lecran: Les trajectoires de $l$ crit - encontra-se à disposiçáo do leitor no IEA para eventual consulta. 